\title{
An Analysis on Monitoring of Healthcare by Means of Internet of Things
}

\author{
Sathish $\mathrm{N}^{\mathrm{a}, 1}$, Valarmathi $\mathrm{K}^{\mathrm{b}}$, Elangovan $\mathrm{G}^{\mathrm{c}}$ \\ ${ }^{a}$ Assistant Professor, Dept of CSE, Panimalar Engineering College Chennai, India \\ ${ }^{b}$ Professor, Dept of CSE, Panimalar Engineering College, Chennai, India \\ ${ }^{c}$ Associate Professor, Dept of CSE, Panimalar Institute of Technology, Chennai, India
}

\begin{abstract}
The convergence of computer science and electronics domain has resulted in the Internet of Things, which is perhaps the most striking innovative outcome (IOT). The Internet of Things (IoT) is a innovative technology with the aim of rapid evolvement by means of numerous new advancements in clinical and wellness areas. Over the last few years, the impact of IOT in medical services has significantly increased. Internet of Things (IoT) based Health-related wearable devices are posing new challenges by incorporating creative innovation and assets. In/out understanding's wellbeing status can be observed intermittently and routinely using wellness wearable gadgets.The Internet of Things (IoT) will profoundly help patient investigation and testing methods due to tiny internet protocol based sensors in a remote location that can be mounted on the patient's body. Currently there are devices with seven billion in value, with expertise predicting the number will rise to ten billion by 2020 and 22 hundred million by 2025. This paper aims to examine and comprehend the utilization of Internet of Things in redesigned healthcare services, as well as how outstanding medical care can be obtained with ease. To summarise, the discussion has been projected on IoT capabilities on remote and detection frameworks and on the relevances utilized on effective medical care applications.
\end{abstract}

Keywords.Internet of Things, Healthcare Monitoring, medical devices, Artificial Intelligence, Machine Learning.

\section{Introduction}

Mostly with advent of technology, the environment has become more portable, and people no longer only interact with one another, but also with objects. The Internet of Things has made it possible to link anything. The Internet of Things binds billions of computers. As a result, this concept simplifies human life. Since the stone age, one of the most important problems that humans have had to contend with is their welfare. Health conditions are more handled and monitored now than they have been in modern memory, thanks to technological advancements. Despite the fact that certain major medical care problems remain unknown, we have come a long way from where we started. Then again, specialists can oversee and counsel patients without any problem. Over these years a few progressed IOT applications has been created to help patients

${ }^{1}$ Sathish N, Assistant Professor, Dept of CSE, Panimalar Engineering College, Chennai, India. Email:nsathishme@gmail.com ${ }^{1}$ 
and clinical officials. IOT causes medical care to improve existing highlights by supporting patient administration, clinical records the board, health related crisis the executives, Treatment the executives and different offices, in this way expanding the nature of medical services applications. Medical clinics use IOT to screen patients constantly and to give ongoing medical care offices. [2,3,4,5,6,7]Internet of things can possibly follow individuals, administrations and item precisely. In this way, examining those information give the exact outcomes. In clinical field exact data lead into the best come about medicines. With IOT specialists can gauge indispensable signs and other bio-metric data of patients with the appended sensors to patients. In this way, the sicknesses and issues could be analyzed rapidly. With the assistance of IOT clinics and rescue vehicle administrations can rapidly get advised when individuals need their administrations in addition with IOT streets and traffic signals can be controlled to help ambulances to arrive at clinic rapidly. [3]. Figure 1 shows the applications ofIoT.

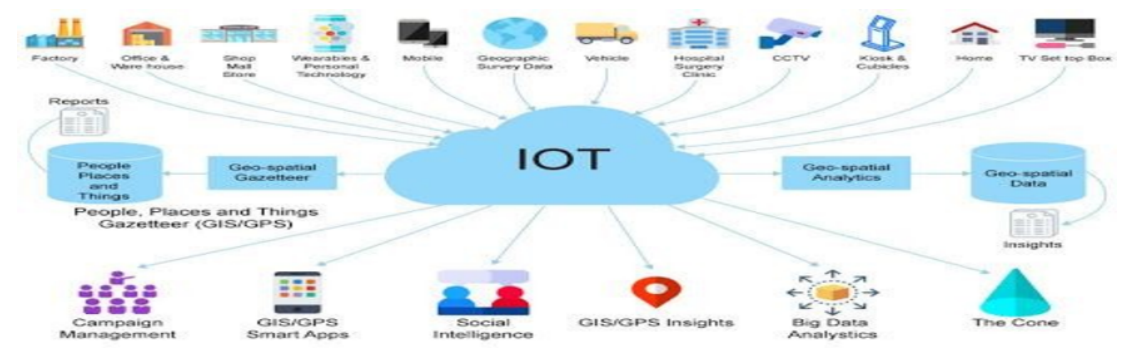

Figure 1.IoT and its applications

\section{Healthcare Environment Based On Iot}

IoT accepts crucial situations within various applications related to medical services. Groupings with respect to customized medical services IoT frameworks are clinical consideration, remote checking, and framework responsiveness. In clinical consideration, patients who are hospitalized especially within basic circumstances, necessitate steady and secure thought to respond somewhat conceivable on to some crisis cases[10][11], which may expand saving the life time of patients. Because of sensors utilized based on IP, the fundamental data concerning wellbeing of patients be able to distantly gathered and shipped off parental figures utilizing the web for additional consideration and examination. This will keep the parental figure from visiting every tolerant checking of status, consequently saves time throughout different mediations [12]. Various wellbeing experts can cooperate to monitor various characteristics of patients, each utilizing based on personage qualities, and examining their movement abiding the data assembled with respect to sensors. Thus, getting affirmation that a patient is in a crisis condition will transform into a straightforward undertaking[13].In remote checking, some more seasoned and more youthful patients, just as persistently debilitated patients, ought to be examined consistently. Distant observing will assist thesepatients with trying not to make outings to the wellbeing community to be checked. Considering their basic status, a few changes in their prosperity will go unseen until a disease arrives at the place of crisis. In framework responsiveness, the opinion of patient's condition is perceived [14] with their 
environmental factors that altogether helps medical services experts to combine all affecting varieties that impact the wellbeing of individual patients. Also, the distinction in the state of being of a patient may broaden the level of its weakness to infection and be an explanation behind their diminishing in prosperity [16].The Table 1 depicts the various utilization of IoT in Healthcare environment[15].

Table 1. Healthcare Variants Analysis

\begin{tabular}{|c|c|}
\hline $\begin{array}{l}\text { Autho } \\
\text { r }\end{array}$ & Description of the Literature \\
\hline \multirow[t]{2}{*}{ Chao Lia et al 2017[6] } & $\begin{array}{l}\text { - With unavoidable observing framework } \\
\text { actual indications of patients areshipped }\end{array}$ \\
\hline & $\begin{array}{l}\text { off far off } \quad \text { clinicalapplication } \\
\text { progressively. }\end{array}$ \\
\hline Shruti Gotadki et al 2014[1] & $\begin{array}{l}\text { - Getting patients to emergency clinic at the } \\
\text { ideal time isn't simple on account of the } \\
\text { gridlocks in the urban areas and } \\
\text { cooperations. }\end{array}$ \\
\hline Lei Yu et al. 2012[2] & $\begin{array}{l}\text { - The proposed framework has capacity to } \\
\text { carry out data trade, savvy acknowledgment. } \\
\text { Situating, following, observing. This } \\
\text { framework has a few key advances. }\end{array}$ \\
\hline $\begin{array}{l}\text { Deepika Mathuvanthi et al } \\
\text { 2019[7] }\end{array}$ & $\begin{array}{l}\text { - The research is planned to distinguish } \\
\text { surprising perspectives and personality of } \\
\text { the patients who has despondency, } \\
\text { nervousness or stress. . }\end{array}$ \\
\hline Haleem et al 2019[5] & $\begin{array}{l}\text { Researchers have proposed strategies } \\
\text { howIOT can help muscular health patients to } \\
\text { improve the nature of medicines.sensors } \\
\text { give the estimation of bone and crack data } \\
\text { rapidly. }\end{array}$ \\
\hline Diaasalama et al 2018[4] & $\begin{array}{l}\text { - This research work proposed a medical care } \\
\text { answer for patients and their guardians to } \\
\text { determine this issue with a savvypill } \\
\text { box with cutting edge highlights. }\end{array}$ \\
\hline Abo-Zahhad et al 2014[3] & $\begin{array}{l}\text { - Researchers have proposed a framework to } \\
\text { give Expert based medical care to } \\
\text { understaffed distant locales through IOT } \\
\text { calledtelemedicine. }\end{array}$ \\
\hline
\end{tabular}


Ashlesha et al. 2017[8]

VaniYeri et al. 2020[9]
- There are a few issues found in IoT and existing wellbeing checking. New innovations could assist with limitingthem by accomplishing the better quality just as electronic security idea.

- The proposed framework is carried out for remote wellbeing observing of thepatients.

\section{Relevances Of Iot In Healthcare}

Medical care devices that are essential for an informative environment provide modern quality by automating procedures, facilitating collaboration, and securely managing data. Smart platforms provide clinicians with easy access to patient records, minimise costs, and boost productivity improvements, all of which lead to a better clinical care [18]. Several examples are providedhere.Any quiet's biometrics are tested separately by setting patient-explicit limit settings in scalable and continuous pulse observing. A patient's ECG pulse (HR) (counting HR inconstancy and HR unwavering quality), breath rate, action level, and body position can all be screened using such a system. Additional instruments can be used in order to remotely track vital signs such as circulatory strain and weight. A cadence testing system can be used in conjunction with beat observing to better comprehend the cardiovascular component of unexplained manifestations. Other clinical uses of such a framework incorporate arrhythmia drug treatment to screen treatment viability, postablation systems to screen cardiovascular musicality, and the checking of vitals, for example the distant checking of heart mood breath and movement[19].

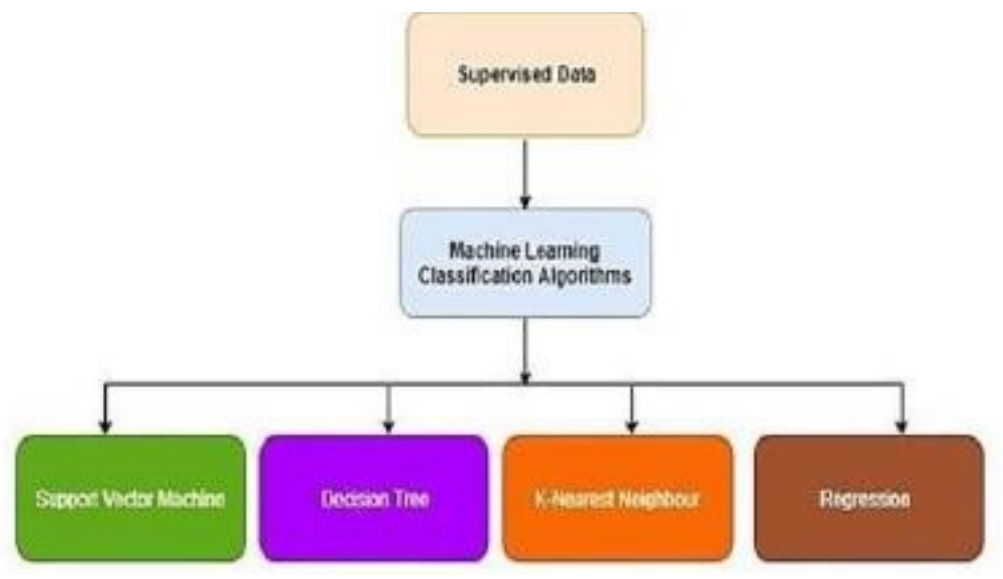

Figure 2.Classifications of Machine Learning Algorithms

In future work, the above examples can be implemented using machine learning algorithms which is depicted in Figure2. 


\section{Conclusion}

The present discussion emphasized on various dissemination modes related to Healthcare monitoring using Internet of Things. We have also discussed on the value of the Internet of Things in the healthcare sector, which is a study of healthcare and protection. It has clarified the IoT's utilization in the sector related to healthcare and confirmed about the much intrinsic IoT transition in environment based on healthcare is presently instantaneous in coordination with efficient machine learning algorithms in future.

\section{References}

[1] ShrutiGotadki, Radhika Mohan, MazharAttarwala , Prof. M.P. Gajare 2014,.Intelligent Ambulance, International Journal of Engineering and Technical Research.Volume-2, Issue-4,pp 49-51.

[2] Lei Yu, Yang Lu, XiaoJuan Zhu 2012. Smart Hospital based on Internet of Things. Journal Of Networks, vol. 7, NO. 10,pp1654-1651

[3] M. Abo-Zahhad, Sabah M. Ahmed, and O. Elnahas 2014. A Wireless Emergency Telemedicine System for Patients Monitoring and Diagnosis. International Journal of Telemedicine and Applications,https://doi.org/10.1155/2014/380787

[4] DiaaSalama Abdul Minaam, MohamedAbd-ELfattah 2018, Smart drugs:Improving healthcare using Smart Pill Box for Medicine Reminder and Monitoring System, Future Computing and Informatics Journal ,Volume 3, Issue 2, December 2018, Pages443-456.

[5] Haleem A, Javaid M, Khan IH 2019, Internet of things (IoT) applications in orthopaedics, Journal of Clinical Orthopaedics and Trauma doi: https://doi.org/10.1016/j.jcot.2019.07.003.

[6] Chao Lia, Xiangpei Hu , Lili Zhang 2017 ,The IoT-based heart disease monitoring system for pervasive healthcare service, Procedia Computer Science, Vol 112 pp2328-2334.

[7] DeepikaMathuvanthi P, V. Suresh, Ch. Pradeep 2019, IoT Powered Wearable to Assist Individuals Facing Depression Symptoms, International Research Journal of Engineering and Technology, Vol 6,pp:1676-1681.

[8] Ashlesha A. Patil, S. R. Suralkar 2017, Review on-IoT Based Smart Healthcare System, International Journal of Advanced Research in Engineering and Technology, Volume 8, Issue 3, pp. 37-42.

[9] VaniYeri, Shubhangi D C 2020, IoT based Real Time Health Monitoring, Proceedings of the Second International Conference on Inventive Research in Computing Applications (ICIRCA-2020),pp980984.

[10] Why is IoT important? https://www.oracle.com/internet-of-things/whatis- iot.html acceded on 1/1/2020 Accessed date1/1/2020.

[11] S.M. Thaung, H.M. Tun, K.K. Win, M.M Than, Exploratory Data Analysis Based on Remote Health Care Monitoring System by Using IoT, Communications, vol. 8, issue 1, pp. 1-8,2020.

[12] J.B Arora, S. Kaushik, IoT in Education: A Future of Sustainable Learning, in Handbook of Research on the Internet of Things Applications in Robotics and Automation, IGI Global, pp. 300-317, 2020.

[13] R. Rajaseskaran, R. Jain, M. Sruthi, Patient Health Monitoring System and Detection of Atrial Fibrillation, Fall, and Air Pollutants Using IoT Technologies, in Incorporating the Internet of Things in Healthcare Applications and Wearable Devices, IGI Global, pp. 165-183,2020.

[14] G.S. Fischer, R.D.R. Righi, V.F. Rodrigues, C.A. da Costa, Use of Internet of Things with Data Prediction on Healthcare Environments: A Survey, International Journal of E-Health and Medical Communications (IJEHMC), vol 11, issue 2, pp. 1-9, Apr2020..

[15] A Survey on Internet of Things and Cloud Computing for Healthcare https://www.mdpi.com/20799292/8/7/768/htm. Accessed date1/1/2020

[16] Agarwal, Technologies in Health Care Domain: A Systematic Review, International Journal of eCollaboration (IJeC), vol. 16, issue 1, pp. 33-44, Jan2020.

[17] K. Sabarinathan et.al ., “ Machine Maintenance Using Augmented Reality”, 3rd International Conference on Communication and Electronics Systems (ICCES), 2018. (DOI: 10.1109/CESYS.2018.8723900) 